\title{
CORRELATION BETWEEN NUTRITIONAL STATUS AND PNEUMONIA AMONG 6-59 MONTHS YEARS OLD IN TANGERANG, BANTEN
}

\author{
Zico Permadi, Maria Ekawati, Citra Ayu Aprilia
}

Faculty of Medicine, Universitas Pembangunan Nasional Veteran Jakarta

\begin{abstract}
Background: Pneumonia is still causing the most deaths among children in developing countries. This disesase often occurs in children under 5 years of age. Nutritional status is a factor that is closely related to infectious diseases such as pneumonia. This study aimed to examine the correlation between nutritional status and pneumonia among 6-59 months years old in Tangerang, Banten.

Subject and Methods: A cross-sectional study was conducted at Pakuhaji Community Health Center, Tangerang, Banten, from January to February 2018. A total of 29 children under five were enrolled in this study. The dependent variable was pneumonia. The independent variable was nutritional status. The data were collected from direct measurement of the children under five and questtioner. The data were analyzed by Chi-square.

Results: As many as 16 children under five (55.17\%) had pneumonia, 7 children under five (24.13\%) were malnutrition, 3 children under five (10.34\%) were short, and 5 children under five (7.24\%) were thin. Nutritional status based on weight for age and weight for height had differences in nutritional status with the incidence of pneumonia among children under five, and they were statistically significant $(\mathrm{p}<0.001)$.

Conclusion: Nutritional status is associate with the incidence of pneumonia among 6-59 months years old (children under five) in Tangerang, Banten.
\end{abstract}

Keywords: pneumonia incidence rate, pneumonia, nutritional status, chidren under five

Correspondence:

Citra Ayu Aprilia. Faculty of Medicine, Universitas Pembangunan Nasional Veteran Jakarta.

Email: citra.ayuaprilia@gmail.com. Mobile: +628122090545

The $7^{\text {th }}$ International Conference on Public Health

Solo, Indonesia, November 18-19, 2020 | 193 https://doi.org/10.26911/the7thicph.03.13 